\title{
Author Correction: Public Trust in Government and Compliance with Policy during the COVID-19 Pandemic: Empirical Evidence from Vietnam
}

\author{
Van Thanh $\mathrm{Vu}^{1}{ }^{\mathbb{C}}$ \\ Published online: 28 October 2021 \\ () Springer Science+Business Media, LLC, part of Springer Nature 2021
}

\section{Author Correction: Public Organization Review https://doi.org/10.1007/s11115-021-00566-w}

The original version of this article unfortunately contained mistakes which are listed below.

- Page 1:

- The letter "D" in "During" in the title of the article should not be capitalized.

- Page 4:

- A new paragraph starts after H1 as the lead-in for hypothesis 2 and it should be re-indented to the left. The paragraph starts from "The complicated and dangerous course of the COVID-19 pandemic..., the following hypothesis was developed".

- Page 5:

- Delete the word "Hypothesis 2"

- The paragraph after "Hypothesis 2" is the lead-in for hypothesis 3 and should be re-indented to the left. The paragraph starts from "Successful control of past pandemics..., the following hypothesis was developed".

The original article can be found online at https://doi.org/10.1007/s11115-021-00566-W.

Van Thanh Vu

vanvuajc@gmail.com

1 Academy of Journalism and Communication, Hanoi, Vietnam 
- Page 9:

- Redundant " $=0=$ " in " $p=0=.021 " ;$ "SD $=0=.85 " ;$ and "SD $=0=.95 "$ ". It should be corrected as " $\mathrm{p}=.021$ "; " $\mathrm{SD}=.85$ "; and " $\mathrm{SD}=.95$ " respectively.

- Page 10:

- Redundant "=" in " $p<0=.05$ ". It should be corrected as " $p<.05$ ".

- Page 11:

- Redundant " $=$ " in " $r=0=.370 "$ and " $\mathrm{p}<0=.001$ ". It should be corrected as " $\mathrm{r}=.370$ " and " $\mathrm{p}<.001$ " respectively.

- The following same mistakes should be corrected: " $\mathrm{r}=0=.443$ " $\rightarrow$ " $\mathrm{r}=$ $.443 " ; " r=0=.358 " \rightarrow$ "r $=.358 " ;$ " $r=0=.404 " \rightarrow$ "r $=.404 " ;$ and " $\mathrm{p}<$ $0=.001 " \rightarrow$ "p $<.001 "$

- Page 12:

- The following mistakes should be corrected: " $r=0=.367 " \rightarrow$ " $r=.367$ "; " $p$ $<0=.001 " \rightarrow$ " $\mathrm{p}=.001 "$

- Page 15:

- A space is missing between "Akira" and "Nakamura".

The original article has been corrected.

Publisher's Note Springer Nature remains neutral with regard to jurisdictional claims in published maps and institutional affiliations. 